\title{
Cytotoxicity of Crude Extract and Isolated Constituents of the Dichrostachys cinerea Bark towards Multifactorial Drug-Resistant Cancer Cells
}

\author{
Armelle T. Mbaveng $\mathbb{D}^{1,2}$ Francois Damen, ${ }^{3}$ James D. Simo Mpetga, ${ }^{3}$ \\ Maurice D. Awouafack, ${ }^{3}$ Pierre Tane $\mathbb{D}^{\mathrm{D}},{ }^{3}$ Victor Kuete $\mathbb{D}^{1,},{ }^{1,2}$ and Thomas Efferth $\mathbb{D}^{1}$ \\ ${ }^{1}$ Department of Pharmaceutical Biology, Institute of Pharmacy and Biochemistry, University of Mainz, \\ Staudinger Weg 5, 55128 Mainz, Germany \\ ${ }^{2}$ Department of Biochemistry, Faculty of Science, University of Dschang, P.O. Box 67, Dschang, Cameroon \\ ${ }^{3}$ Department of Chemistry, Faculty of Science, University of Dschang, P.O. Box 67, Dschang, Cameroon
}

Correspondence should be addressed to Victor Kuete; kuetevictor@yahoo.fr and Thomas Efferth; efferth@uni-mainz.de Received 10 February 2019; Accepted 17 June 2019; Published 8 July 2019

Academic Editor: Ghee T. Tan

Copyright (C) 2019 Armelle T. Mbaveng et al. This is an open access article distributed under the Creative Commons Attribution License, which permits unrestricted use, distribution, and reproduction in any medium, provided the original work is properly cited.

\begin{abstract}
The effectiveness of anticancer chemotherapy is greatly impeded by the resistance of malignant cells to cytotoxic drugs. In this study, the cytotoxicity of the crude extract (DCB) and compounds isolated from the bark of Dichrostachys cinerea, namely, betulinic acid (1), glyceryl-1-hexacosanoate (2), 7-hydroxy-2-(4-hydroxyphenyl)-4H-chromen-4-one (3), and 6-hydroxy-2-(4-hydroxyphenyl)$4 H$-chromen-4-one (4), was investigated. The study was extended to the assessment of the mode of induction of apoptosis by DCB and compound $\mathbf{1}$. The resazurin reduction assay was used for cytotoxicity studies. Assessments of cell cycle distribution, apoptosis, mitochondrial membrane potential (MMP), and reactive oxygen species (ROS) were performed by flow cytometry. Constituents of DCB were isolated by column chromatography. Triterpenoid $\mathbf{1}$ and flavone $\mathbf{4}$ had cytotoxic effects towards the 9 tested cancer cell lines with $\mathrm{IC}_{50}$ values below $50 \mu \mathrm{M}$. The recorded $\mathrm{IC}_{50}$ values varied from $7.65 \mu \mathrm{M}$ (towards multidrug-resistant CEM-ADR5000 leukemia cells) to $44.17 \mu \mathrm{M}$ (against HepG2 hepatocarcinoma cells) for 1, 18.90 $\mu \mathrm{M}$ (CCRF-CEM leukemia cells) to $88.86 \mu \mathrm{M}$ (against HCT116p53 $3^{++}$colon adenocarcinoma cells) for 4 , and $0.02 \mu \mathrm{M}$ (against CCRF-CEM cells) to $122.96 \mu \mathrm{M}$ (against CEM/ADR5000 cells) for doxorubicin. DCB induced apoptosis in CCRF-CEM cells mostly mediated by MMP alteration and enhanced ROS production; compound $\mathbf{1}$ induced apoptosis through caspases activation and MMP alteration and increased ROS production. Dichrostachys cinerea is an interesting cytotoxic plant and deserves more studies leading to new antineoplastic agents to fight cancer and mostly leukemia.
\end{abstract}

\section{Introduction}

Recent data from the World Health Organization revealed that most countries still face an increase in cancer incidences [1]. The global cancer burden reached 18.1 million new cases in 2018, with one in eight men and one in 11 women dying in developing countries [1]. Worldwide, the five-year prevalence of cancer is estimated at 43.8 million people [1]. The effectiveness of anticancer chemotherapy is greatly impeded by the resistance of malignant cells to cytotoxic drugs [2]. The search for new antiproliferative drugs should therefore take into consideration the ability of cancer cells to develop resistant phenotypes. Natural products are well recognized as source of cytotoxic molecules [3]. Various studies have previously documented the effectiveness of botanicals and phytochemicals from the flora of Africa to fight cancer multidrug resistance (MDR) [4, 5]. However, research should be intensified to increase the library of cytotoxic plants and molecules available in the African flora, in order to have better chances of achieving clinically exploitable drugs in the future. The present study was hence designed to evaluate the cytotoxicity of crude extract and compounds from the bark of Dichrostachys cinerea (L.) Wight \& Arn. (Fabaceae) towards a panel of drug-sensitive 
and drug-resistant cancer cell lines. The mode of induction of apoptosis of crude extract and compound $\mathbf{1}$ was further investigated. Dichrostachys cinerea, also known as sicklebush, Bell mimosa, Chinese lantern tree, or Kalahari Christmas tree, is a fast growing tree of up to $7 \mathrm{~m}$ height, traditionally used as laxative, diuretic and to treat dysentery, elephantiasis, gonorrhoea, boils, headache, syphilis, sore, worms $[6,7]$, inflammation, and cancer [8]. Previous phytochemical analysis of Dichrostachys cinerea led to the identification of a triterpenoid $\beta$-amyrin glucoside, apigenin-7-O-apiosyl $(1 \longrightarrow 2)$ glucoside, chrysoeriol-7-O-apiosyl $(1 \longrightarrow 2)$ glucoside, clovamide, quercetin-3-O-rhamnopyranoside, quercetin-3$O$-glucopyranoside, myricetin-3-O-rhamnopyranoside, myricetin-3-O-glucopyranoside, myricetin, apigenin, and kaempferol from the leaves $[6,9]$ as well as the meroterpene derivatives, dichrostachines A-R from the bark and roots [10]. Preliminary cytotoxicity investigations of this plant were reported towards DU145 and 22Rv1 prostate cancer cells and HeLa cervical cancer cells [7]. This is the first intensive study on the potential of Dichrostachys cinerea and some of its constituents against MDR cancer cell lines.

\section{Materials and Methods}

2.1. Plant Material and Extraction. Dichrostachys cinerea barks were collected in February 2017 in Bazou $\left(5^{\circ} 4^{\prime}\right.$ $\left.0^{\prime \prime} \mathrm{N}, 10^{\circ} 28^{\prime} 0^{\prime \prime} \mathrm{E}\right)$ in the West Region of Cameroon. The plant was identified at the National Herbarium of Cameroon (Yaoundé), where voucher is available under number $34028 / \mathrm{HNC}$. The bark of $D$. cinerea was air-dried and powdered $(2000 \mathrm{~g})$ and then macerated in $20 \mathrm{l}$ of ethanol for $48 \mathrm{~h}$. The solvent was evaporated in vacuum under reduced pressure to give the crude extract (170 g; DCB).

2.2. Isolation of Compounds from the Bark of Dichrostachys cinerea. An aliquot of DCB (160 g) was treated with ethyl acetate (EtOAc) to give two subextracts: the EtOAc extract (DCA, 85g) and the methanol (MeOH) extract (DCB, 75g). DCA (85 g) was submitted to a silica gel flash column chromatography (CC) using dichloromethane $\left(\mathrm{CH}_{2} \mathrm{Cl}_{2}\right)$-EtOAc and EtOAc-MeOH mixtures of increasing polarity. Fractions of $150 \mathrm{ml}$ each were collected as follows: $\mathrm{CH}_{2} \mathrm{Cl}_{2} 100 \%$ (subfrs 1-8), $\mathrm{CH}_{2} \mathrm{Cl}_{2}$-EtOAc 95:5 (sub-frs 9-19), $\mathrm{CH}_{2} \mathrm{Cl}_{2}$-EtOAc 90:10 (sub-frs 20-23), $\mathrm{CH}_{2} \mathrm{Cl}_{2}$-EtOAc 80:20 (sub-frs 24-30), $\mathrm{CH}_{2} \mathrm{Cl}_{2}$-EtOAc 60:40 (sub-frs 31-35), $\mathrm{CH}_{2} \mathrm{Cl}_{2}$-EtOAc 50:50 (sub-frs 36-40), EtOAc100\% (sub-frs 41-45), EtOAc- $\mathrm{MeOH}$ 95:20 (sub-frs 46-52), EtOAc-MeOH 90:10 (sub-frs 53-60), EtOAc-MeOH 80:20 (sub-frs 61-64), EtOAc-MeOH 70:30 (sub-frs 65-68), and $\mathrm{MeOH} 100 \%$ (sub-frs 69-72). These fractions were then pooled on the basis of their analytical thin layer chromatography (TLC) profiles into five fractions (frs) as follows: DCA1 (Sub-frs 1-6; $10 \mathrm{~g}$ ), DCA2 (Sub-frs 7-14; $12 \mathrm{~g}$ ), DCA3 (Sub-frs 15-30; 13 g), DCA4 (Sub-frs 31-60; 20 g), and DCA5 (Sub-frs 61-72; $25 \mathrm{~g}$ ). From a direct filtration of fraction DCA2, followed by further Sephadex CC, compound 1 was obtained as a white powder $(1 \mathrm{~g})$.

An aliquot of DCA5 (18 g) was submitted to silica gel flash $\mathrm{CC}$ using $\mathrm{CH}_{2} \mathrm{Cl}_{2}$-EtOAc and EtOAc-MeOH mixtures of increasing polarity. 110 subfractions (sub-frs) of $150 \mathrm{ml}$ each were collected as follows: $\mathrm{CH}_{2} \mathrm{Cl}_{2} 100 \%$ (sub-frs 122), $\mathrm{CH}_{2} \mathrm{Cl}_{2}$-EtOAc 95:5 (sub-frs 23-53), $\mathrm{CH}_{2} \mathrm{Cl}_{2}$-EtOAc 90:10 (sub-frs 54-59), $\mathrm{CH}_{2} \mathrm{Cl}_{2}$-EtOAc 85:15 (sub-frs 6075), $\mathrm{CH}_{2} \mathrm{Cl}_{2}$-EtOAc 80:20 (sub-frs 76-83), $\mathrm{CH}_{2} \mathrm{Cl}_{2}$-EtOAc 75:25 (sub-frs 84-91), $\mathrm{CH}_{2} \mathrm{Cl}_{2}$-EtOAc 70:30 (sub-frs 92-95), $\mathrm{CH}_{2} \mathrm{Cl}_{2}$-EtOAc 60:40 (sub-frs 96-100), EtOAc100\% (sub-frs 101-104), EtOAc-MeOH 90:10 (sub-frs 105-107), and $\mathrm{MeOH}$ $100 \%$ (sub-frs 108-110). Compound 3 was obtained as a white powder (14 mg) in sub-frs 27-31; sub-frs 30-35 afforded compound 2 as yellow powder (15 mg); meanwhile, sub-frs $37-44$ yielded compound 4 as yellow powder (15 mg).

2.3. General Procedure. All general chemistry procedures (mass spectral data, ${ }^{1} \mathrm{H}$ and ${ }^{13} \mathrm{C}$ nuclear magnetic resonance (NMR) spectra) and CC were performed with the same apparatus and reagents, and in similar experimental conditions as reported earlier [13].

2.4. Cell Cultures. Drug-sensitive and drug-resistant cancer cell lines of previously reported origin were used in this study. These included drug-sensitive CCRF-CEM leukemia cells and its multidrug-resistant P-glycoprotein-overexpressing subline CEM/ADR5000 cells [14-16], MDA-MB-231-pcDNA breast cancer cells and their resistant subline MDA-MB-231-

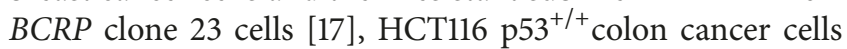
and their knockout clone HCT116 p53-/- cells, and U87.MG glioblastoma cells and their resistant subline U87.MG $\triangle E G F R$ cells $[18,19]$. Normal AML12 hepatocytes were used and compared with HepG2 hepatocarcinoma cells $[18,19]$.

2.5. Cytotoxicity Assay. The cytotoxicity assay performed using resazurin reduction assay was applied to the crude extract (DCB), compounds 1-4, and doxorubicin [18, 20, 21] with similar experimental conditions as those reported earlier $[13,19,22,23]$. The Infinite M2000 Pro $^{\mathrm{TM}}$ plate reader (Tecan, Crailsheim, Germany) with excitation wavelength of $544 \mathrm{~nm}$ and an emission wavelength of $590 \mathrm{~nm}$ was used to read the fluorescence after $72 \mathrm{~h}$ incubation. $\mathrm{IC}_{50}$ values earlier defined [13] were calculated from a calibration curve by linear regression using Microsoft Excel [24]. The degree of resistance (D.R.) was determined as the $\mathrm{IC}_{50}$ value of the resistant cell line versus that of its sensitive congeners; meanwhile, the selectivity index (S.I.) was the $\mathrm{IC}_{50}$ value in normal AML12 hepatocytes versus that in HepG2 hepatocarcinoma.

\footnotetext{
2.6. Cell Cycle Analysis and Detection of Apoptotic Cells by Flow Cytometry and Annexin V/PI Staining. Aliquots of $1 \times 10^{6}$ CCRF-CEM cells were treated with the studied samples (DCB and compound 1), the reference drug (doxorubicin), or the solvent control (DMSO) at various concentrations. The distribution of CCRF-CEM cycle was analyzed as described earlier in similar experimental conditions (24 h incubation; humidified $5 \% \mathrm{CO}_{2}$ atmosphere; $\left.37^{\circ} \mathrm{C}\right)[13,22,23]$. The $\mathrm{BD}$ Accuri C6 Flow Cytometer (BD Biosciences, Heidelberg, Germany) was used to measure the propidium iodide (PI) fluorescence of individual nuclei. Assays were repeated at least three times and in triplicate.
} 

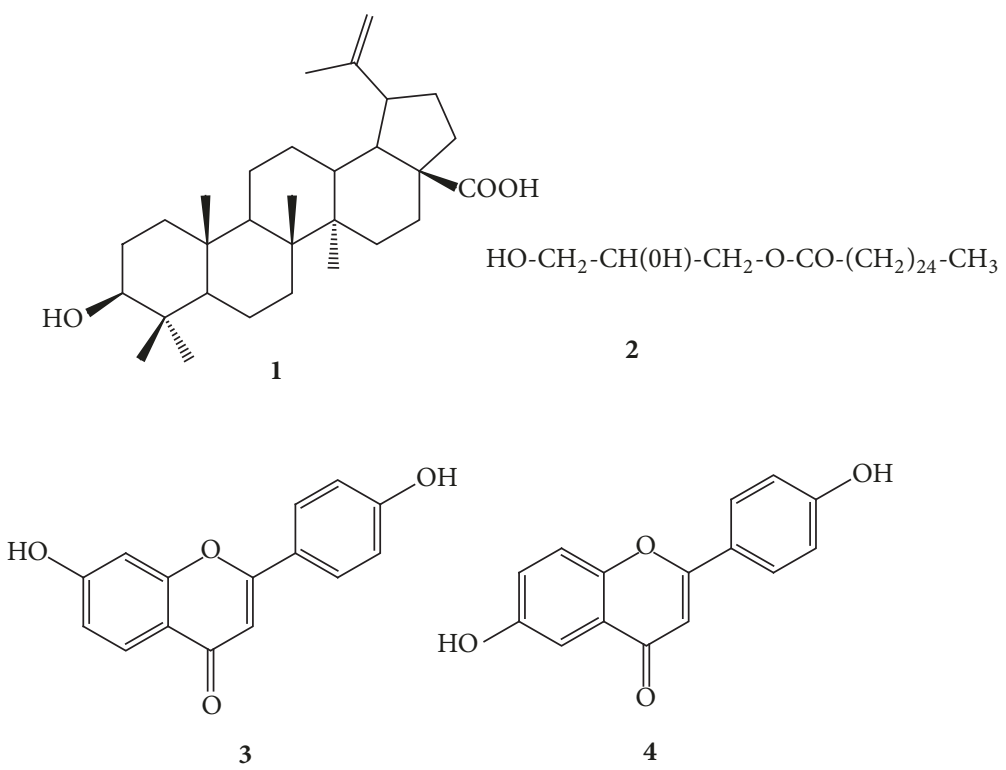

Figure 1: Chemical structure of compounds isolated from the bark of Dichrostachys cinerea. 1: betulinic acid; 2: glyceryl-1-hexacosanoate; 3: 7-hydroxy-2-(4-hydroxyphenyl)-4H-chromen-4-one; and 4: 6-hydroxy-2-(4-hydroxyphenyl)-4H-chromen-4-one.

To perform the annexin V/PI staining, DCB, betulinic acid (1), and doxorubicin were used to treat an amount of $1 \times 10^{6}$ per $1 \mathrm{ml}$ CCRF-CEM cells. The experimental conditions were similar to those earlier reported ( $24 \mathrm{~h}$ incubation; humidified $5 \% \mathrm{CO}_{2}$ atmosphere; $37^{\circ} \mathrm{C}$ ) [13]. The $\mathrm{BD}$ Accuri C6 Flow Cytometer was then used to analyze apoptosis using fluorescein isothiocyanate (FITC)-conjugated annexin V/PI assay kit (eBioscience ${ }^{\mathrm{TM}}$ Annexin V; Invitrogen, San Diego, USA) similarly as reported earlier [13, 22, 23]; early apoptosis for cells stained with only annexin V; late apoptosis or in a necrotic stage for cells stained with both annexin $\mathrm{V}$ and propidium iodide $[13,25,26]$.

2.7. Assessment of Caspases Activation Using the Caspase-Glo Assay. After $6 \mathrm{~h}$ treatment of CCRF-CEM cells with DCB and triterpenoid 1 for $6 \mathrm{~h}$, caspases activities were evaluated with Caspase-Glo 3/7, 8, and 9 assay kits (Promega, Mannheim, Germany) similarly as previously reported $[13,18,27]$.

2.8. Assessment of the Integrity of the Mitochondrial Membrane. The mitochondrial membrane potential (MMP) of CCRF-CEM cells was analyzed after $24 \mathrm{~h}$ treatment with DCB, compound $\mathbf{1}$, or valinomycin (mitochondrial gradient dissipation substance or positive control). The $5,5^{\prime}, 6,6^{\prime}$ tetrachloro-1,1',3,3' -tetraethylbenzimidazolyl carbocyanine iodide (JC-1; Biomol, Hamburg, Germany) staining was used to measure the MMP similarly as previously reported $[13,18,22,23]$.

2.9. Evaluation of the Production of Reactive Oxygen Species (ROS). The measurement of ROS production using $2^{\prime}, 7^{\prime}$-dichlorodihydrofluorescein diacetate $\left(\mathrm{H}_{2} \mathrm{DCFH}-\mathrm{DA}\right)$ (Sigma-Aldrich) was done in CCRF-CEM cells were treated with DCB, compound 1, a solvent control (DMSO), or a positive control, hydrogen peroxide $\left(\mathrm{H}_{2} \mathrm{O}_{2}\right)$ for $24 \mathrm{~h}$, in similar experimental conditions as documented earlier $[13,18,28,29]$.

\section{Results}

3.1. Phytochemistry. Physical and NMR data with direct comparison with literature was used to elucidate the chemical structures of phytochemicals isolated from the bark of Dichrostachys cinerea. They were betulinic acid, $\mathrm{C}_{30} \mathrm{H}_{50} \mathrm{O}$ (1; m.p. $216^{\circ} \mathrm{C} ; \mathrm{m} / z$ 426) [30], glyceryl-1-hexacosanoate, $\mathrm{C}_{29} \mathrm{H}_{58} \mathrm{O}_{4}$ (2; m.p. 91-93 ${ }^{\circ} \mathrm{C} ; \mathrm{m} / z$ 470) [31], 7-hydroxy-2(4-hydroxyphenyl)-4H-chromen-4-one, $\mathrm{C}_{15} \mathrm{H}_{10} \mathrm{O}_{4}$ (3; m.p. $315^{\circ} \mathrm{C} ; \mathrm{m} / z$ 254) [32], and 6-hydroxy-2-(4-hydroxyphenyl)$4 \mathrm{H}$-chromen-4-one, $\mathrm{C}_{15} \mathrm{H}_{10} \mathrm{O}_{4}\left(4 ;\right.$ m.p. $\left.325^{\circ} \mathrm{C} ; \mathrm{m} / z 254\right)$ [33] (Figure 1).

3.2. Cytotoxicity. Triterpenoid $\mathbf{1}$ and flavone $\mathbf{4}$ had cytotoxic effects towards the 9 tested cancer cell lines with $\mathrm{IC}_{50}$ values below $50 \mu \mathrm{M}$ (Table 1). Botanical DCB and flavone 3 had selective activities, while no cytotoxic effect $\left(\mathrm{IC}_{50}\right.$ value above $100 \mu \mathrm{M}$ ) was recorded with fatty acid ester 2. The recorded $\mathrm{IC}_{50}$ values varied from $7.65 \mu \mathrm{M}$ (towards resistant CEM-ADR5000 leukemia cells) to $44.17 \mu \mathrm{M}$ (against HepG2 hepatocarcinoma cells) for $1,18.90 \mu \mathrm{M}$ (CCRFCEM leukemia cells) to $88.86 \mu \mathrm{M}$ (against HCT116p53 ${ }^{+/+}$ colon adenocarcinoma cells) for 4 , and $0.02 \mu \mathrm{M}$ (against CCRF-CEM cells) to $122.96 \mu \mathrm{M}$ (against CEM/ADR5000 cells) for doxorubicin. The $\mathrm{IC}_{50}$ values in normal AML12 hepatocytes were above $80 \mu \mathrm{g} / \mathrm{mL}$ for DCB and above 100 $\mu \mathrm{M}$ for compounds $\mathbf{2}$ and $\mathbf{3}$ (Table 1). Collateral sensitivity (hypersensitivity or D.R. below 1) of all resistant cell lines compared to their sensitive counterparts was observed with triterpenoid 1 (Table 1). Hypersensitivity or normal sensitivity 


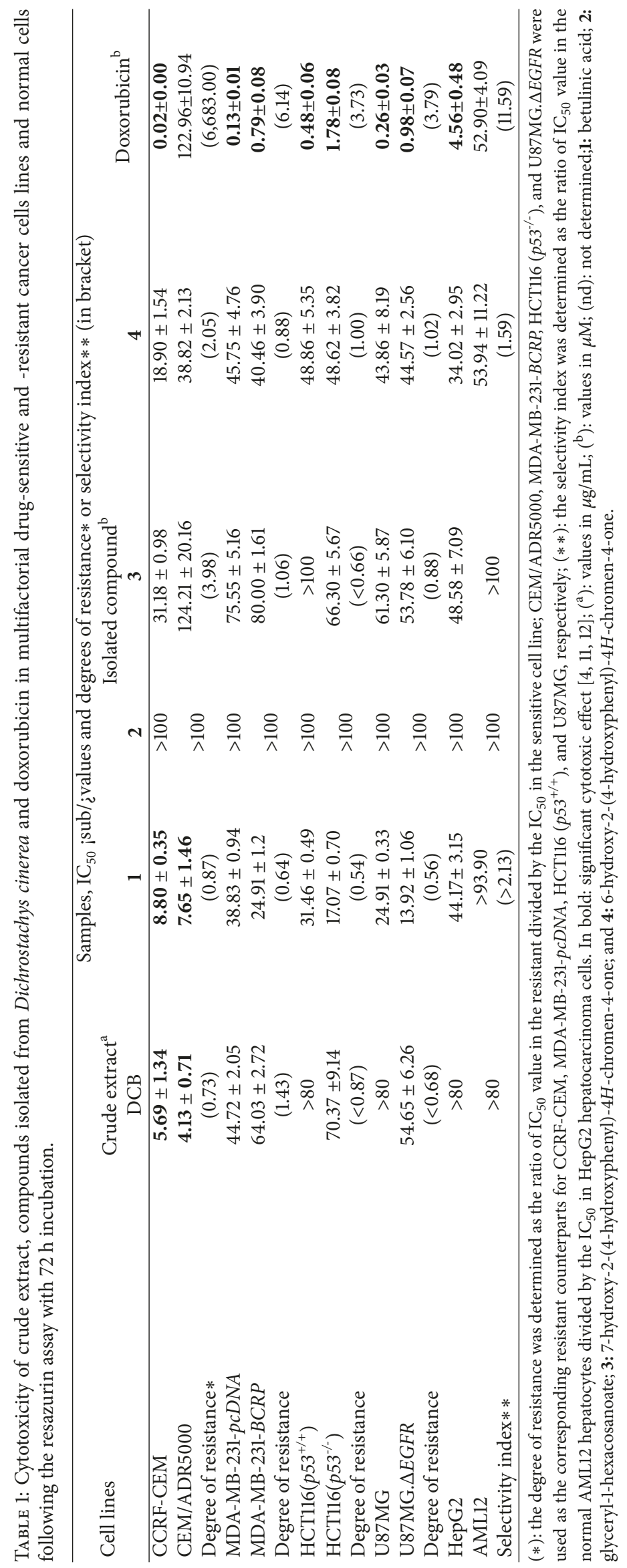



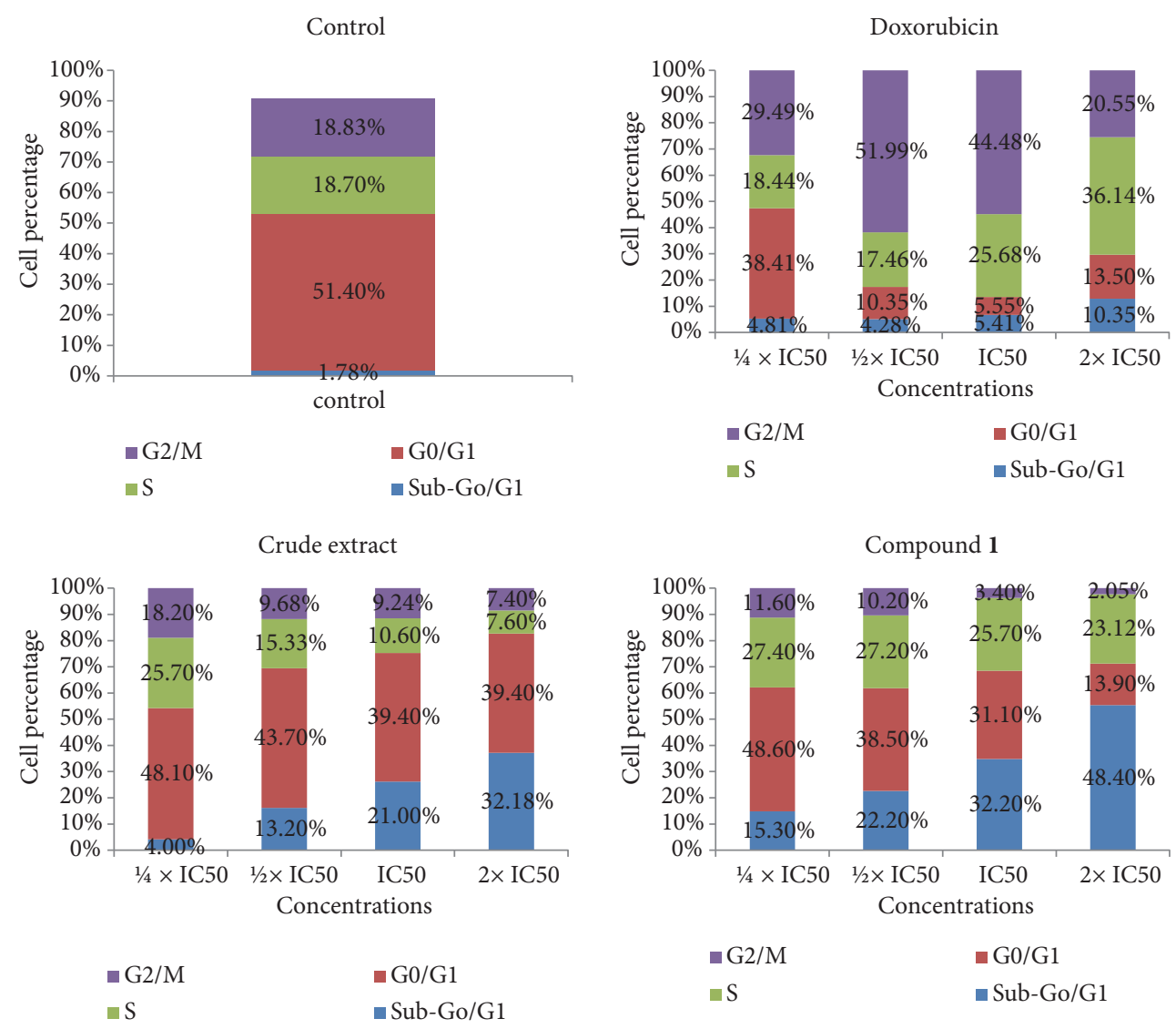

FIGURE 2: Distribution of CCRF-CEM leukemia cell cycle upon $24 \mathrm{~h}$ treatment with crude extract, betulinic acid (1), and doxorubicin. $\mathrm{IC}_{50}$ values were $5.69 \mu \mathrm{g} / \mathrm{ml}$ for the crude extract, $8.80 \mu \mathrm{M}$ for $\mathbf{1}$, and $0.02 \mu \mathrm{M}$ for doxorubicin.

of at least one resistant cell line to botanical DCB as well as compounds 3 and $\mathbf{4}$ was also recorded (Table 1). Selectivity indexes above 2 were also observed with compound 1 (S.I.: >2.13) and doxorubicin (S.I.: 11.59) in HepG2 as compared with normal AML12 hepatocytes (Table 1).

3.3. Cell Cycle Distribution and Apoptosis. Upon treatment of CCRF-CEM cells with botanical DCB, triterpenoid $\mathbf{1}$, and the reference compound doxorubicin, the cell cycle phases were modified in concentration-dependent manner (Figure 2). Increase of cells in sub-G0/G1 phase was observed with all samples, and DCB induced cell cycle arrest in G0/G1 phase, while triterpenoid 1 caused cycle arrest in $G 2 / \mathrm{M}$; doxorubicin induced arrest of cell cycle between $\mathrm{S}$ and G2/M. The percentage of CCRF-CEM cells in sub-G0/G1 phase in nontreated cells only was $1.78 \%$; meanwhile, it varied upon treatment from $4.00 \%\left(1 / 4 \times \mathrm{IC}_{50}\right)$ to $32.18 \%\left(2 \times \mathrm{IC}_{50}\right)$ for $\mathrm{DCB}, 15.30 \%\left(1 / 4 \times \mathrm{IC}_{50}\right)$ to $48.40 \%\left(2 \times \mathrm{IC}_{50}\right)$ for compound 1 , and $4.81 \%\left(1 / 4 \times \mathrm{IC}_{50}\right)$ to $10.35 \%\left(2 \times \mathrm{IC}_{50}\right)$ for doxorubicin (Figure 2). These data suggested that DCB, compound 1, and doxorubicin induced apoptosis in CCRF-CEM cells. In the annexin V/PI staining, the induction of apoptosis was further investigated. The results depicted in Figure 3 showed a dose-dependent induction with DCB, triterpenoid $\mathbf{1}$, and doxorubicin. When cells were treated with $2 \times \mathrm{IC}_{50}$, for example, DCB induced apoptosis with $39.8 \%$ early apoptotic
$\mathrm{V}(+) / \mathrm{PI}(-)$ cells, $8.8 \%$ late apoptotic V (+)/PI (+) cells as well as necrosis with $12.8 \%$ annexin $\mathrm{V}(-) / \mathrm{PI}(+)$ cells; triterpenoid 1 induced $51.0 \%$ early apoptotic cells and $5.1 \%$ necrotic cells, while doxorubicin induced $11.8 \%$ late apoptotic cells.

3.4. Activation of Caspases, Integrity of $M M P$, and ROS Production. Treatment of CCRF-CEM cells with DCB did not activate the activity of caspases $3 / 7,8$, and 9 contrary to triterpenoid 1 (Figure 4). In effect, a dose-dependent activation of caspases upon treatment with 1 was observed, with optimal effects at $8.8 \mu \mathrm{M}$; up to 3.19-fold, 2.91-fold, and 2.37-fold increases in the activity of caspases $3 / 7,8$, and 9 , respectively, were recorded.

The effects of DCB, betulinic acid (1), and valinomycin on integrity of MMP in CCRF-CEM are depicted in Figure 5. Both DCB and compound 1 considerably modified the MMP with up to $90.3 \%$ and $57.5 \%$ (at $2 \times \mathrm{IC}_{50}$ ), respectively; valinomycin at $10 \mu \mathrm{M}$ induced $45.9 \%$ alteration.

The effects of DCB and compound 1 on the production of ROS in CCRF-CEM cells are given in Figure 6. The two samples dose-dependently enhanced the production of ROS in CCRF-CEM cells. The ROS level in nontreated cells was $0.2 \%$, whilst at $2 \times \mathrm{IC}_{50}$, DCB caused increased ROS production by up to $61.1 \%$ and triterpenoid 1 by $53.30 \% . \mathrm{H}_{2} \mathrm{O}_{2}$ induced ROS production by $98.8 \%$ at $50 \mu \mathrm{M}$. 

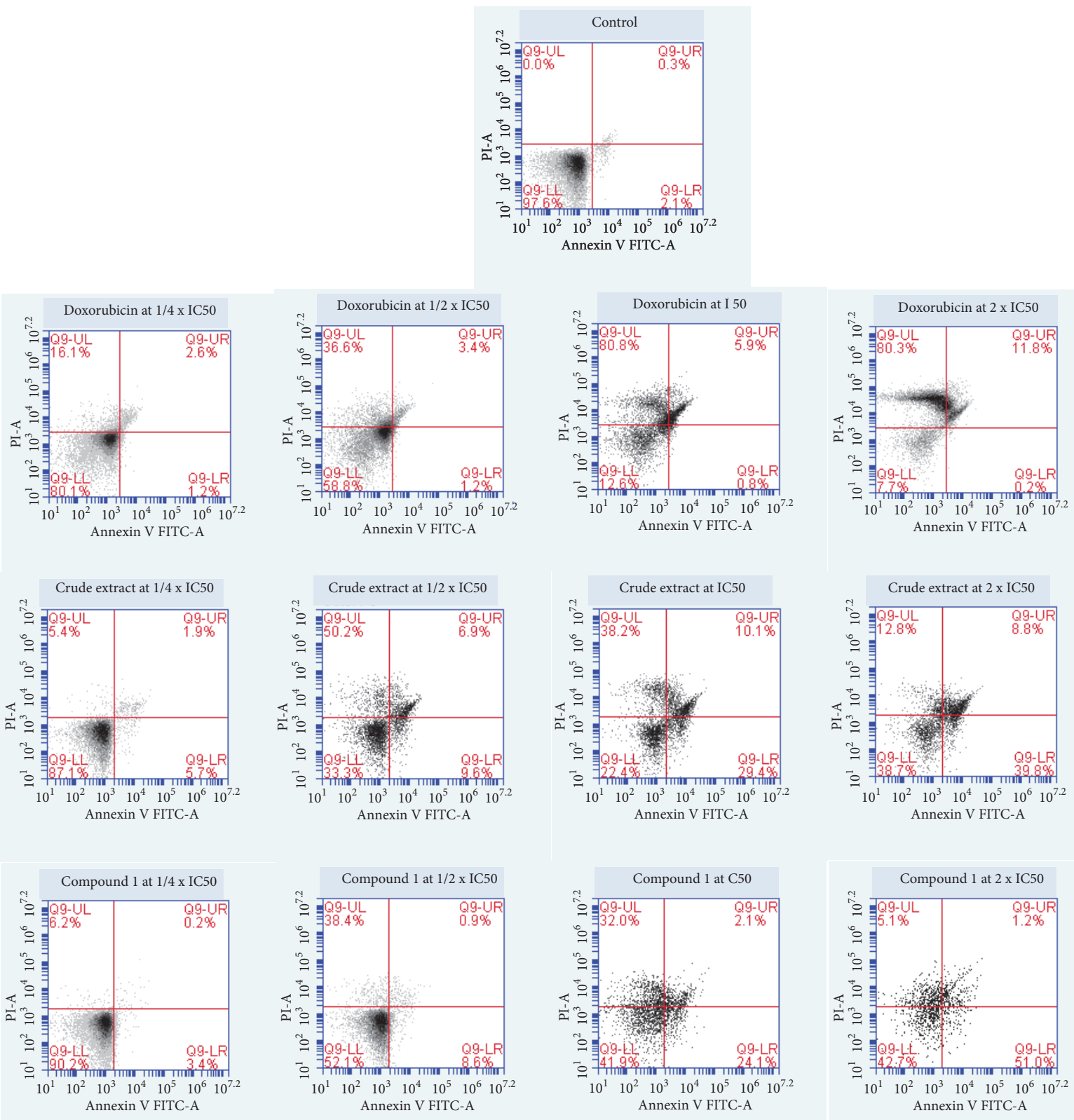

FIGURE 3: Evaluation of apoptosis induced by the crude extract, betulinic acid (1), and doxorubicin on CCRF-CEM leukemia cells after 24 $\mathrm{h}$ as determined by annexin V/PI assay. Apoptosis was assessed by flow cytometry after annexin V-PI double staining. $\mathrm{IC}_{50}$ values were 5.69 $\mu \mathrm{g} / \mathrm{mL}$ for the crude extract, $8.80 \mu \mathrm{M}$ for 1 , and $0.02 \mu \mathrm{M}$ for doxorubicin. Necrotic cells lose membrane integrity, allowing PI entry. Q9-LL: viable cells exhibit annexin V (-)/PI (-); Q9-LR: early apoptotic cells exhibit annexin (+)/PI (-); and Q9-UR and Q9-UL: late apoptotic cells or necrotic cells exhibit annexin V (+)/PI (+) or annexin V (-)/PI (+).

\section{Discussion}

Phytochemicals isolated from the bark of Dichrostachys cinerea were one triterpenoid $\mathbf{1}$, one ester of fatty acid $\mathbf{2}$, and two flavone-type flavonoids $\mathbf{3}$ and $\mathbf{4}$. Previous phytochemical investigation of the bark of Dichrostachys cinerea led to the isolation of meroterpene derivatives, dichrostachines A-R [10] which were not isolated in this study, probably due to the isolation procedure used or the fact that the plant was harvested in different geographic locations.
Drug resistance of malignant cells seriously hampers the chemotherapy of cancer. In the search for cytotoxic compounds, scientists should take into consideration the ability of these cells to rapidly develop drug resistance. This is possible when investigations also consider resistant phenotypes of malignant cells. In the present study, we have used several models of MDR cancer cell lines including ATPbinding cassette (ABC)-transporter-overexpressing MDRmediating P-glycoprotein (P-gp; ABCB1/MDR1) or breast cancer resistance protein (ABCG2/BCRP), a p53 knockout 


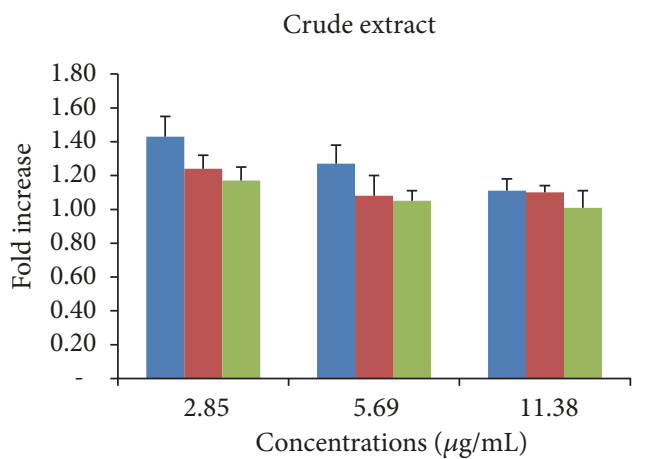

- caspase $3 / 7$

- Caspase 8

- Caspase 9

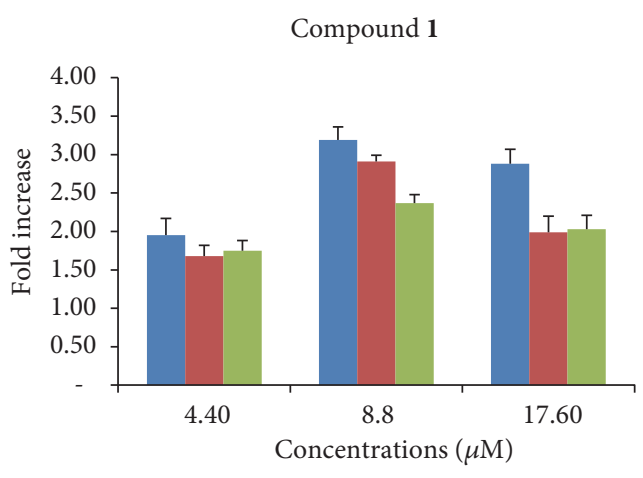

aspase $3 / 7$

- Caspase 8

Caspase 9

FIGURE 4: Effects of $6 \mathrm{~h}$ treatment of CCRF-CEM cells with crude extract and betulinic acid (1) on caspases activity. Samples were tested at their $1 / 2 \times \mathrm{IC}_{50}, \mathrm{IC}_{50}$ and $2 \times \mathrm{IC}_{50} ; \mathrm{IC}_{50}$ values were $5.69 \mu \mathrm{g} / \mathrm{mL}$ for the crude extract and $8.80 \mu \mathrm{M}$ for 1 . Caspase activity is expressed as percentage (\%) compared to untreated cells. Shown are mean \pm SD of three independent experiments.
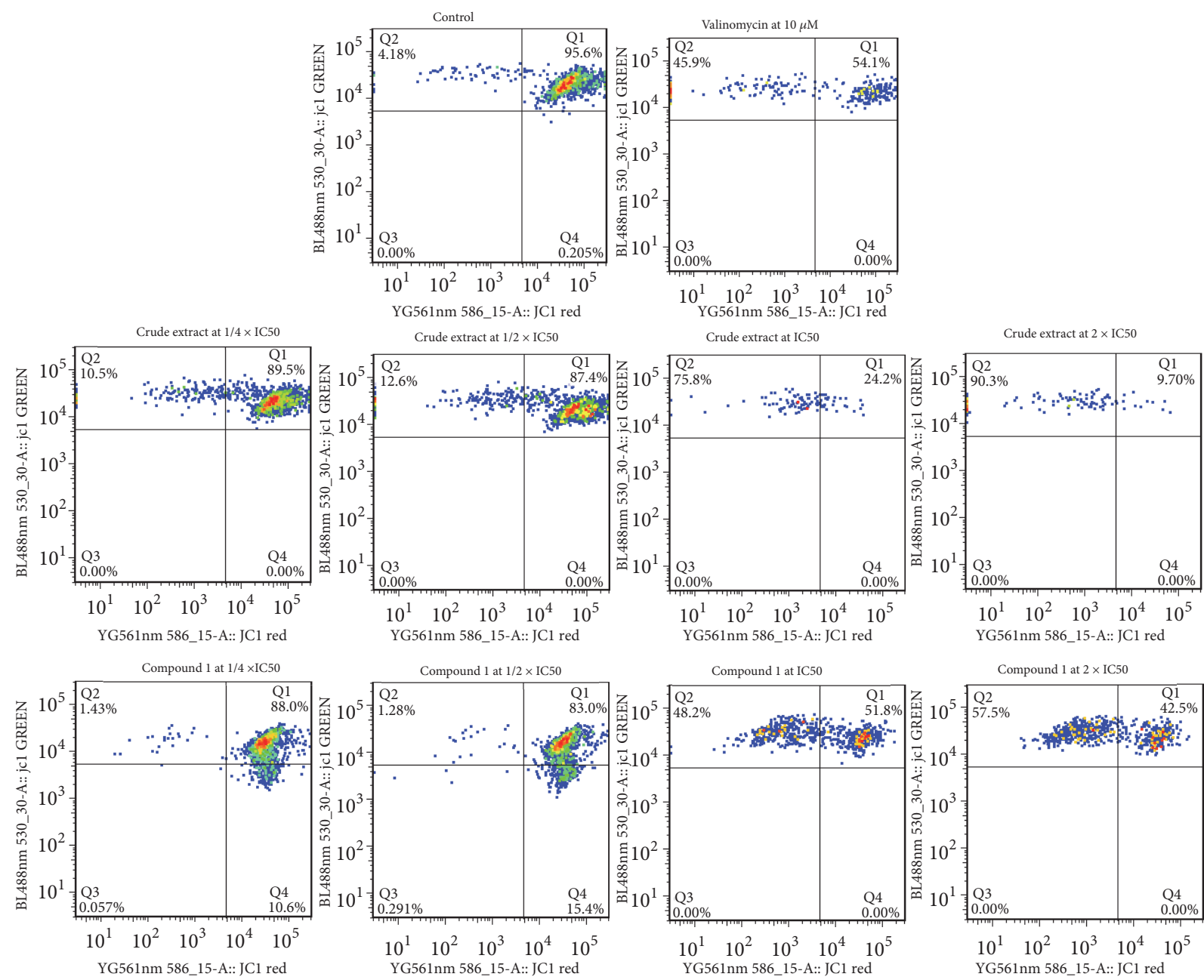

FIGURE 5: Effect of the crude extract, betulinic acid (1) and valinomycin for $24 \mathrm{~h}$ on the MMP of CCRF-CEM cells. IC ${ }_{50}$ values were 5.69 $\mu \mathrm{g} / \mathrm{ml}$ for the crude extract, $8.80 \mu \mathrm{M}$ for $\mathbf{1}$, and $0.02 \mu \mathrm{M}$ for doxorubicin. Intact cells (Q1), loss of MMP (Q2), and ruptured cell membrane (Q3 and Q4). 

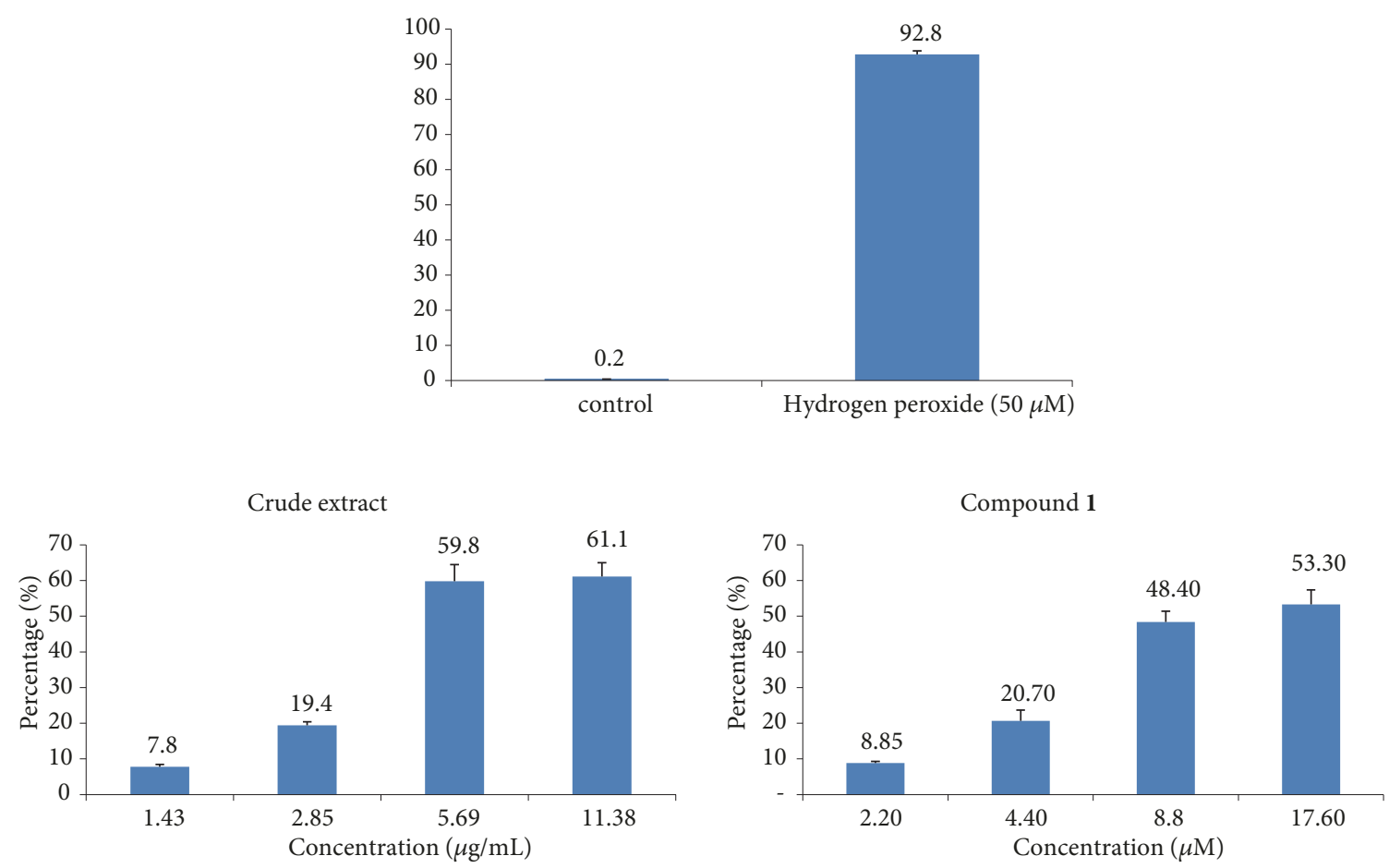

FIGURE 6: ROS production in CCRF-CEM cells treated for $24 \mathrm{~h}$ with the crude extract, betulinic acid (1), and hydrogen peroxide $\left(\mathrm{H}_{2} \mathrm{O}_{2}\right)$. Samples were tested at their $1 / 4 \times \mathrm{IC}_{50}, 1 / 2 \times \mathrm{IC}_{50}, \mathrm{IC}_{50}$, and $2 \times \mathrm{IC}_{50} ; \mathrm{IC}_{50}$ values were $5.69 \mu \mathrm{g} / \mathrm{mL}$ for the crude extract and $8.80 \mu \mathrm{M}$ for 1 . Shown are mean $\pm \mathrm{SD}$ of three independent experiments.

cell line, and a mutation-activated EGFR gene ( $\triangle \mathrm{EGFR})$ cell line. The resistant P-gp overexpressing CEM/ADR5000 cells treated with the crude extract DCB were collaterally sensitive [5] compared to their sensitive parental subline CCRF-CEM cells (Table 1). Hypersensitivity of all resistant cell lines to betulinic acid as compared to their respective sensitive counterparts was also observed; for flavones 3 and 4, the hypersensitivity or otherwise normally sensitive (D.R. below or around 1) of at least three resistant cell lines was also recorded. Generally, the D.Rs. recorded upon treatments with DCB, compounds $\mathbf{1}, \mathbf{3}$, and $\mathbf{4}$ were lower than with doxorubicin (Table 1). Previous studies also reported the hypersensitivity of CEM/ADR5000 leukemia cells to compound $\mathbf{1}$ as compared to its sensitive congener CCRF-CEM cells [34]. These data are indications that Dichrostachys cinerea and its constituents have the potential to combat cancer multidrug resistance. According to the National Cancer Institute USA (NCI), good botanicals should exert their cytotoxicity with $\mathrm{IC}_{50}$ values below $20 \mu \mathrm{g} / \mathrm{ml}$ upon $48 \mathrm{~h}$ or $72 \mathrm{~h}$ incubation [11], while this set point is $10 \mu \mathrm{M}$ for phytochemicals [11, 12]. Also, NCI recommends that botanicals yielding $\mathrm{IC}_{50}$ values below or around $30 \mu \mathrm{g} / \mathrm{ml}$ should undergo purification to isolate cytotoxic molecules [35]. In this work, $\mathrm{IC}_{50}$ values as low as $4.69 \mu \mathrm{g} / \mathrm{ml}$ and $4.13 \mu \mathrm{g} / \mathrm{ml}$ were recorded with the crude extract DCB, on both sensitive and resistant leukemia cells, respectively (Table 1 ). Selective and lower $\mathrm{IC}_{50}$ values were recorded with DCB on carcinoma cells, clearly indicating that this plant could likely be used to combat leukemia. This was also the case with betulinic acid (1), as $\mathrm{IC}_{50}$ values below 10 $\mu \mathrm{M}$ were also recorded towards leukemia cells, and higher values obtained in carcinoma cells. Though flavones $\mathbf{3}$ and $\mathbf{4}$ had cytotoxic effects in several cell lines including leukemia and carcinoma phenotypes, all $\mathrm{IC}_{50}$ values obtained were above $10 \mu \mathrm{M}$. This confirms the hypothesis that this plant and its constituents could mostly be used in the fight against leukemia. The good S.I. (>2) of compound $\mathbf{1}$ also indicates that it can be used in chemotherapy (Table 1). In effect, the low cytotoxicity of betulinic acid towards the normal PBL peripheral blood lymphoblast was also reported [36]. However, its lower S.I. as compared to that of doxorubicin, clinically associated with many adverse effects to patients (despite higher S.I.), clearly indicates that further studies on the toxicity of this compound as well as the crude extract will be necessary.

To the best of our knowledge, this is the first intensive study on cytotoxicity of Dichrostachys cinerea and its constituents 3 and $\mathbf{4}$ against MDR cancer cell lines. However, preliminary antiproliferative effects of this plant were reported towards DU145 and 22Rv1 prostate cancer cells and HeLa cervical cancer cells, with the lowest $\mathrm{IC}_{50}$ values of 8.04 $\mu \mathrm{g} / \mathrm{ml}$ recorded in $22 \mathrm{Rv} 1$ cells [7]. Also, betulinic acid is a well-known cytotoxic compound [34]. Its effects have been reported towards several cancer cell lines including sensitive and resistant phenotypes such as CCRF-CEM cells and CEM/ADR5000 leukemia cells, MDA-MB-231-pcDNA and MDA-MB-231/BCRP breast adenocarcinoma cells, HEK293 and HEK293/ABCB5 embryonic kidney cells, and U87.MG and U87.MG $\triangle E G F R$ glioblastoma cells with $\mathrm{IC}_{50}$ values 
ranging from $15.1 \mu \mathrm{M}$ (against HEK293 cells) to $29.4 \mu \mathrm{M}$ (towards CCRF-CEM cells) $[34,36]$.

In this study, the crude extract DCB and triterpenoid $\mathbf{1}$ had the best cytotoxic effects on the two leukemia cells with $\mathrm{IC}_{50}$ values below $10 \mu \mathrm{M}$. They were consequently selected for further cellular mechanistic studies towards CCRF-CEM cells, such as induction of apoptosis, caspases activation, and alteration of MMP as well as the production of ROS [37]. DCB and compound $\mathbf{1}$ induced apoptosis in CCRF-CEM cells (Figures 2 and 3). Induction of apoptosis by DCB was mediated by MMP alteration and increased ROS production, while that induced by triterpenoid 1 was mediated by caspases activation (Figure 4), MMP alteration (Figure 5), and increased ROS production (Figure 6). Previous studies on the molecular mechanism of the cytotoxic action of compound 1 showed that it inhibited P-gp, BCRP, and ABCB5 and mutation activated EGFR overexpressing cells. Besides, various genes significantly correlated to its activity on cell cycle regulation, microtubule formation, signal transduction, transcriptional regulation, chromatin remodeling, cell adhesion, tumor suppression, ubiquitination, and proteasome degradation [34].

\section{Conclusions}

The present study indicated that Dichrostachys cinerea is a potential cytotoxic plant and should be further explored to develop new antineoplastic agents to fight recalcitrant cancers. The crude extract DCB induced apoptosis in CCRFCEM cells mostly mediated by MMP alteration and enhanced ROS production; compound $\mathbf{1}$ induced apoptosis through caspases activation and MMP alteration and increased ROS production.

\section{Abbreviations}

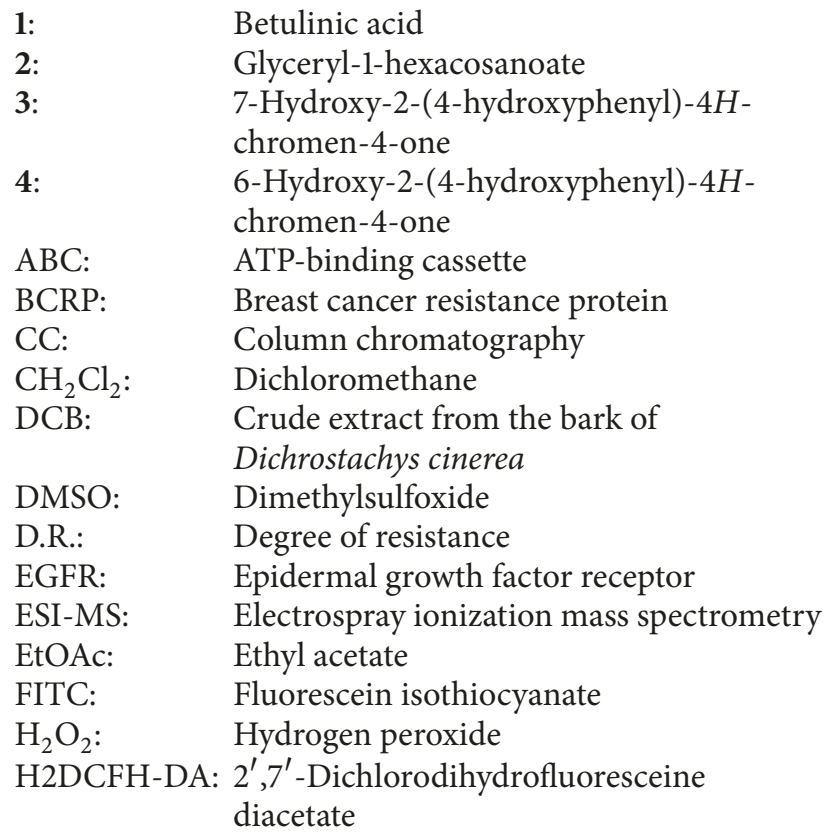

JC-1: $\quad 5,5^{\prime}, 6,6^{\prime}$-Tetrachloro-1,1 $1^{\prime}, 3,3^{\prime}$ tetraethylbenzimidazolylcarbocyanine iodide

$\mathrm{IC}_{50}: \quad 50 \%$ inhibitory concentration

MDR: Multidrug resistance

MeOH: Methanol

MMP: Mitochondrial membrane potential

NMR: Nuclear magnetic resonance

P-gp: P-glycoprotein

PI: $\quad$ Propidium iodide

ROS: Reactive oxygen species

Sub-frs: Subfractions

TLC: Thin layer chromatography

TMS: Tetramethylsilane.

\section{Data Availability}

The data used to support the findings of this study are included within the article.

\section{Conflicts of Interest}

The authors declare that there are no conflicts of interest regarding the publication of this paper.

\section{Authors' Contributions}

Armelle T. Mbaveng and Francois Damen carried out the experiments. Victor Kuete, Pierre Tane, and Thomas Efferth designed the study. Maurice D. Awouafack performed NMR experiments. Francois Damen, Maurice D. Awouafack, and James D. Simo Mpetga contributed to structural elucidation. Armelle T. Mbaveng and Victor Kuete wrote the manuscript. Thomas Efferth supervised the work, corrected the manuscript, and provided the facilities for the study. All authors read and approved the final manuscript.

\section{Acknowledgments}

Funding was provided by the Alexander von Humboldt $(\mathrm{AvH})$ foundation (Grant no.: CMR 1163890 GF-E to ATM). Armelle T. Mbaveng is thankful to AvH Foundation for an 18-month fellowship in Prof. Dr. Thomas Efferth's Laboratory in Mainz, Germany, through the "Georg Foster Research Fellowship for Experienced Researcher" program. ATM is also grateful to the AvH Foundation for the return fellowship to the University of Dschang. Authors are also thankful to the Institute of Molecular Biology gGmbH (IMB) (Mainz, Germany), where the flow cytometry experiments were performed.

\section{Supplementary Materials}

Supplementary file.docx. RMN ${ }^{1} \mathrm{H}, 13 \mathrm{C}$ and major chemical shifts of studied compounds, betulinic acid (1), glyceryl1-hexacosanoate (2), 7-hydroxy-2-(4-hydroxyphenyl)-4Hchromen-4-one (3), and 6-hydroxy-2-(4-hydroxyphenyl)$4 H$-chromen-4-one (4). (Supplementary Materials) 


\section{References}

[1] IARC, "Latest global cancer data: cancer burden rises to 18.1 million new cases and 9.6 million cancer deaths in 2018," Tech. Rep., International Agency for Research on Cancer, 2018.

[2] C. Fitzmaurice, D. Dicker, A. Pain et al., "The global burden of cancer 2013," JAMA Oncology, vol. 1, no. 4, pp. 505-527, 2015.

[3] N. P. Gullett, A. R. M. Ruhul Amin, S. Bayraktar et al., "Cancer prevention with natural compounds," Seminars in Oncology, vol. 37, no. 3, pp. 258-281, 2010.

[4] V. Kuete and T. Efferth, "African flora has the potential to fight multidrug resistance of cancer," BioMed Research International, vol. 2015, Article ID 914813, 24 pages, 2015.

[5] A. T. Mbaveng, V. Kuete, and T. Efferth, "Potential of central, Eastern and Western Africa medicinal plants for cancer therapy: spotlight on resistant cells and molecular targets," Frontiers in Pharmacology, vol. 8, p. 343, 2017.

[6] R. T. El-Sharawy, A. Elkhateeb, M. M. Marzouk, R. R. Abd El-Latif, S. E. Abdelrazig, and M. A. El-Ansari, "Antiviral and antiparasitic activities of clovamide: the major constituent of Dichrostachys cinerea (L.) wight et arn," Journal of Applied Pharmaceutical Science, vol. 7, no. 9, pp. 219-223, 2017.

[7] P. M. Kimani, P. G. Mwitari, S. Mwenda Njagi, P. Gakio Kirira, and D. M. Kiboi, "In vitro anti-proliferative activity of selected plant extracts against cervical and prostate cancer cell lines," Journal of Cancer Science \& Therapy, vol. 10, no. 9, 2018.

[8] G. F. Ibikunle, S. K. Okwute, and E. O. Ogbadoyi, "Cytotoxic agents from nigerian plants: a case study of Spondias mombin Linn (Anacardiaceae) leaves," FUW Trends in Science \& Technology Journal, vol. 2, no. 1B, pp. 510-513, 2017.

[9] M. Vijayalakshmi, K. Periyanayagam, K. Kavitha, and K. Akilandeshwari, "Phytochemical analysis of ethanolic extract of Dichrostachys Cinerea W and Arn leaves by a thin layer chromatography, high performance thin layer chromatography and column chromatography," Ancient Science of Life, vol. 32, no. 4, pp. 227-233, 2013.

[10] C. Long, L. Marcourt, R. Raux et al., "Meroterpenes from Dichrostachys cinerea inhibit protein farnesyl transferase activity," Journal of Natural Products, vol. 72, no. 10, pp. 1804-1815, 2009.

[11] J. Boik, Natural Compounds in Cancer Therapy, Oregon Medical Press, Minnesota, Minn, USA, 2001.

[12] G. Brahemi, F. R. Kona, A. Fiasella et al., "Exploring the structural requirements for inhibition of the ubiquitin E3 ligase breast cancer associated protein 2 (BCA2) as a treatment for breast cancer," Journal of Medicinal Chemistry, vol. 53, no. 7, pp. 2757-2765, 2010.

[13] A. T. Mbaveng, F. Damen, İ. Çelik, P. Tane, V. Kuete, and T. Efferth, "Cytotoxicity of the crude extract and constituents of the bark of Fagara tessmannii towards multi-factorial drug resistant cancer cells," Journal of Ethnopharmacology, vol. 235, pp. 28-37, 2019.

[14] A. Kimmig, V. Gekeler, M. Neumann et al., "Susceptibility of multidrug-resistant human leukemia cell lines to human interleukin 2-activated killer-cells," Cancer Research, vol. 50, no. 21, pp. 6793-6799, 1990.

[15] T. Efferth, A. Sauerbrey, A. Olbrich et al., "Molecular modes of action of artesunate in tumor cell lines," Molecular Pharmacology, vol. 64, no. 2, pp. 382-394, 2003.

[16] J.-P. Gillet, T. Efferth, D. Steinbach et al., "Microarray-based detection of multidrug resistance in human tumor cells by expression profiling of ATP-binding cassette transporter genes," Cancer Research, vol. 64, no. 24, pp. 8987-8993, 2004.

[17] L. A. Doyle, W. Yang, L. V. Abruzzo et al., "A multidrug resistance transporter from human MCF-7 breast cancer cells," Proceedings of the National Acadamy of Sciences of the United States of America, vol. 95, no. 26, pp. 15665-15670, 1998.

[18] V. Kuete, L. P. Sandjo, J. L. N. Ouete, H. Fouotsa, B. Wiench, and T. Efferth, "Cytotoxicity and modes of action of three naturally occurring xanthones (8-hydroxycudraxanthone G, morusignin $\mathrm{i}$ and cudraxanthone I) against sensitive and multidrug-resistant cancer cell lines," Phytomedicine, vol. 21, no. 3, pp. 315-322, 2014.

[19] V. Kuete, A. T. Mbaveng, L. P. Sandjo, M. Zeino, and T. Efferth, "Cytotoxicity and mode of action of a naturally occurring naphthoquinone, 2-acetyl-7-methoxynaphtho[2,3-b]furan-4,9quinone towards multi-factorial drug-resistant cancer cells," Phytomedicine, vol. 33, pp. 62-68, 2017.

[20] J. O'Brien, O. Wilson, T. Orton, and F. Pognan, "Investigation of the Alamar blue (resazurin) fluorescent dye for the assessment of mammalian cell cytotoxicity," European Journal of Biochemistry, vol. 267, no. 17, pp. 5421-5426, 2000.

[21] V. Kuete, P. D. Tchakam, B. Wiench et al., "Cytotoxicity and modes of action of four naturally occuring benzophenones: 2,2' ,5,6'-Tetrahydroxybenzophenone, guttiferone E, isogarcinol and isoxanthochymol," Phytomedicine, vol. 20, no. 6, pp. 528536, 2013.

[22] A. T. Mbaveng, B. L. Ndontsa, V. Kuete et al., "A naturally occuring triterpene saponin ardisiacrispin B displayed cytotoxic effects in multi-factorial drug resistant cancer cells via ferroptotic and apoptotic cell death," Phytomedicine, vol. 43, pp. 78-85, 2018.

[23] A. T. Mbaveng, G. W. Fotso, D. Ngnintedo et al., "Cytotoxicity of epunctanone and four other phytochemicals isolated from the medicinal plants Garcinia epunctata and Ptycholobium contortum towards multi-factorial drug resistant cancer cells," Phytomedicine, vol. 48, pp. 112-119, 2018.

[24] J. Dzoyem, A. NKuete, V. Kuete et al., "Cytotoxicity and antimicrobial activity of the methanol extract and compounds from Polygonum limbatum," Planta Medica, vol. 78, no. 8, pp. 787-792, 2012.

[25] D. A. Gerwirtz and L. W. Elmore, "Apoptosis as the predominant tumor cell response to chemotherapy and irradiation: a case of TUNEL vision?" Current Opinion in Investigational Drugs, vol. 6, no. 12, p. 1199, 2005.

[26] S. Samarghandian, J. T. Afshari, and S. Davoodi, "Chrysin reduces proliferation and induces apoptosis in the human prostate cancer cell line pc-3," Clinics, vol. 66, no. 6, pp. 10731079, 2011.

[27] V. Kuete, L. P. Sandjo, D. E. Djeussi et al., "Cytotoxic flavonoids and isoflavonoids from Erythrina sigmoidea towards multifactorial drug resistant cancer cells," Investigational New Drugs, vol. 32, no. 6, pp. 1053-1062, 2014.

[28] D. A. Bass, J. W. Parce, L. R. Dechatelet, P. Szejda, M. C. Seeds, and $\mathrm{M}$. Thomas, "Flow cytometric studies of oxidative product formation by neutrophils: a graded response to membrane stimulation," Journal of Immunology, vol. 130, no. 4, pp. 19101917, 1983.

[29] A. Cossarizza, R. Ferraresi, L. Troiano et al., "Simultaneous analysis of reactive oxygen species and reduced glutathione content in living cells by polychromatic flow cytometry," Nature Protocols, vol. 4, no. 12, pp. 1790-1797, 2009. 
[30] S. B. Mahato and A. P. Kundu, “ ${ }^{13}$ C NMR Spectra of pentacyclic triterpenoids-a compilation and some salient features," Phytochemistry, vol. 37, no. 6, pp. 1517-1575, 1994.

[31] R. N. Mbouangouere, P. Tane, D. Ngamga, P. Djemgou, M. I. Choudhary, and B. T. Ngadjui, "Piptaderol from Piptadenia africana," African Journal of Traditional, Complementary and Alternative Medicines, vol. 4, no. 3, pp. 294-298, 2007.

[32] A. O. Oladimeji, I. A. Oladosu, M. S. Ali, and Z. Ahmed, "Flavonoids from the roots of Dioclea reflexa (Hook F.)," Bulletin of the Chemical Society of Ethiopia, vol. 29, no. 3, pp. 441-448, 2015.

[33] H. Yoon, S. Eom, J. Hyun et al., " ${ }^{1} \mathrm{H}$ and ${ }^{13} \mathrm{C}$ NMR data on hydroxy/methoxy flavonoids and the effects of substituents on chemical shifts," Bulletin of the Korean Chemical Society, vol. 32, no. 6, pp. 2101-2104, 2011.

[34] M. E. M. Saeed, N. Mahmoud, Y. Sugimoto, T. Efferth, and H. Abdel-Aziz, "Betulinic acid exerts cytotoxic activity against multidrug-resistant tumor cells via targeting autocrine motility factor receptor (AMFR)," Frontiers in Pharmacology, vol. 9, p. 418, 2018.

[35] M. Suffness and J. Pezzuto, "Assays related to cancer drug discovery," in Methods in Plant Biochemistry: Assays for Bioactivity, K. Hostettmann, Ed., pp. 71-133, Academic Press, London, UK, 1990.

[36] V. Zuco, R. Supino, S. C. Righetti et al., "Selective cytotoxicity of betulinic acid on tumor cell lines, but not on normal cells," Cancer Letters, vol. 175, no. 1, pp. 17-25, 2002.

[37] Y. Fuchs and H. Steller, "Programmed cell death in animal development and disease," Cell, vol. 147, no. 4, pp. 742-758, 2011. 


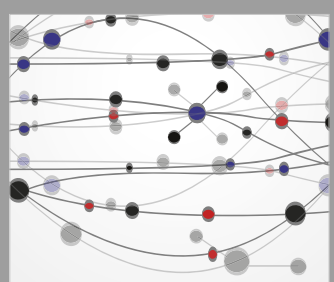

The Scientific World Journal
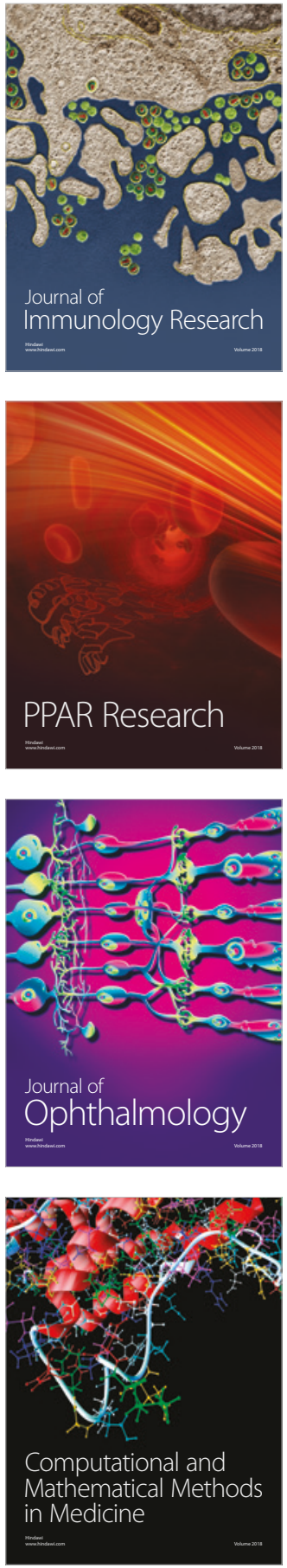

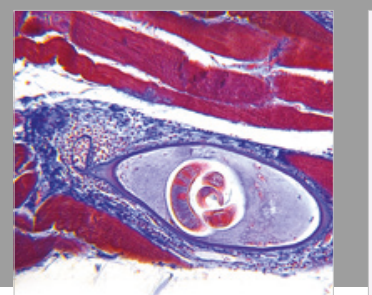

Gastroenterology Research and Practice

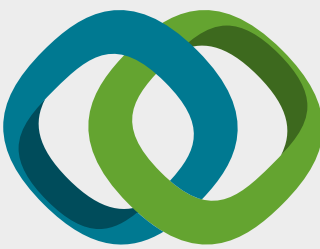

\section{Hindawi}

Submit your manuscripts at

www.hindawi.com
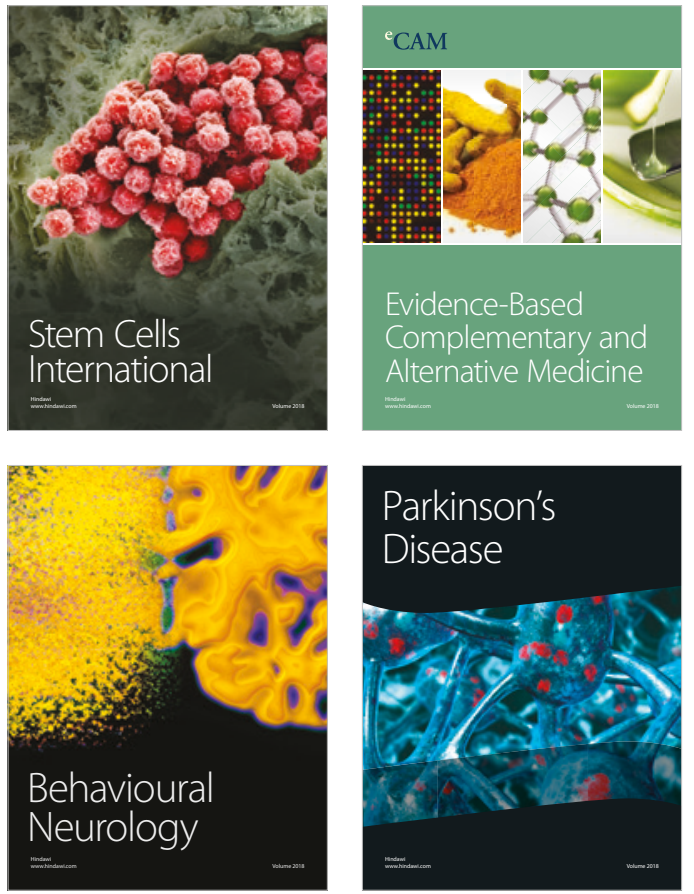

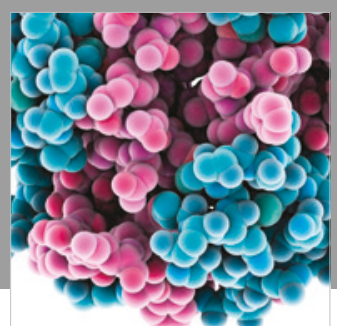

ournal of

Diabetes Research

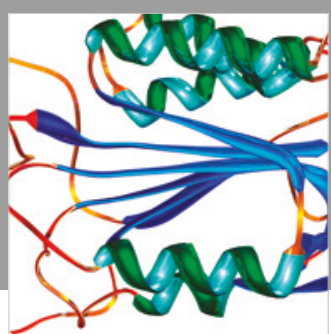

Disease Markers
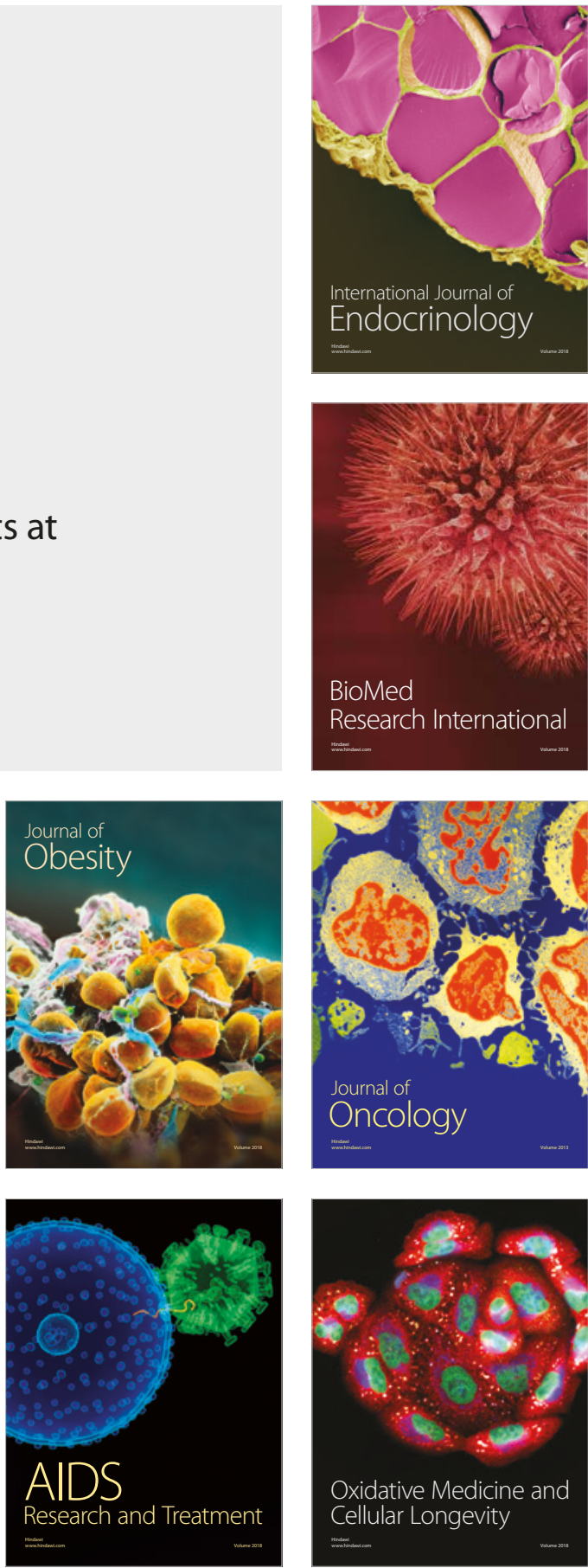